\title{
Evaluation of expression of cancer stem cell markers and fusion gene in synovial sarcoma: Insights into histogenesis and pathogenesis
}

\author{
YANG ZHOU $^{1 *}$, DONGDONG CHEN ${ }^{1 *}$, YAN QI $^{1 *}$, RUIXUE LIU $^{1}$, SHUGANG LI $^{3}$, \\ HONG ZOU $^{1}$, JIAOJIAO LAN ${ }^{1}$, XINXIN JU ${ }^{1}$, JINFANG JIANG ${ }^{1}$, \\ WEIHUA LIANG ${ }^{1}$, YAOYUAN SHEN ${ }^{4}$, LIJUAN PANG ${ }^{1}$ and FENG LI ${ }^{1,2}$

\begin{abstract}
${ }^{1}$ Department of Pathology and Key Laboratory of Xinjiang Endemic and Ethnic Diseases (Ministry of Education), Shihezi University School of Medicine; Department of Pathology, First Affiliated Hospital to Shihezi University School of Medicine, Shihezi, Xinjiang 832002; ${ }^{2}$ Department of Pathology, Beijing Chaoyang Hospital, Capital Medical University, Beijing 100020; ${ }^{3}$ Department of Public Health, Shihezi University School of Medicine, Shihezi, Xinjiang 832000; ${ }^{4}$ Department of Pathology, People's Hospital of Xinjiang Autonomous Region, Urumqi, Xinjiang 830000, P.R. China
\end{abstract} \\ Received September 10, 2016; Accepted February 6, 2017
}

DOI: $10.3892 /$ or.2017.5617

\begin{abstract}
Synovial sarcoma (SS) is an aggressive soft tissue tumor, with uncertain histological and cellular origin. SYT-SSX is considered to be responsible for sarcoma initiation and progression. The histogenesis and pathogenesis of this tumor are poorly understood, and prognosis of patients of SS is unsatisfactory. Recent studies have shown an association of cancer stem cells with the initiation and development of tumors. We explored immunohistochemical expression level of stem cell associated markers to determine the possible histogenesis and pathogenesis of SS. Fusion gene SYT-SSX was tested to assess diagnostic value and the molecular pathological features. We obtained the clinicopathological data of $20 \mathrm{SS}$ patients, immunohistochemical staining were used to evaluate stem cell-associated markers included CD133, CD29, CD44, nestin, and ALDH1. Fusion gene SYT-SSX was tested by reverse transcriptase-polymerase chain reaction (RT-PCR). Twenty
\end{abstract}

Correspondence to: Professor Lijuan Pang, Department of Pathology and Key Laboratory for Xinjiang Endemic and Ethnic Diseases, Shihezi University School of Medicine, North 2nd Road, Shihezi, Xinjiang 832002, P.R. China

E-mail: ocean123456@163.com

Professor Feng Li, Department of Pathology, Beijing Chaoyang Hospital, Capital Medical University, Beijing 100020, P.R. China

E-mail: lifeng7855@126.com

*Contributed equally

Key words: synovial sarcoma, cancer stem cell, SYT-SSX, RT-PCR, immunohistochemistry
SS cases were observed and the positive immunoexpression results showed CD133 (17/20), CD29 (11/20), CD44 (11/20), nestin (6/20), and ALDH1 (5/20). Fusion gene SYT-SSX was successfully detected by RT-PCR from 18 available samples. The expression of stem cell-associated markers (CD133, CD29, CD44, Nestin, and ALDH1) and clinical data (age, gender, sites, tumor size, histological type, tumor stage, and distant metastases) did not show statistically significant relationship ( $P>0.05)$, whereas, statistically significance between ALDH1 and metastases was observed $(\mathrm{P}<0.01)$. The ALDH1 positive synovial sarcoma (ALDH1 ${ }^{+} \mathrm{SS}$ ) cases had significantly poor prognosis compared to ALDH1 negative synovial sarcoma (ALDH1 $\left.{ }^{-} \mathrm{SS}\right)$ cases $(\mathrm{P}<0.05)$. Immunohistochemical results indicated different expression levels of the five cancer stem cell markers in SS suggesting that SS may arise from cancer stem cells. Fusion gene SYT-SSX may play a critical role in the molecular pathological of SS.

\section{Introduction}

Synovial sarcoma (SS) is a malignant tumor that accounts for $7-10 \%$ of soft tissue sarcomas, which arises mostly in young adults with high risk of metastasis and recurrence (1). SS occurs in a wide variety of organs, with higher incidence near the joints of the lower extremities (2). The histological types of SS include biphasic type synovial sarcoma (BSS), monophasic type synovial sarcoma (MSS), and poorly differential type synovial sarcomas (PDSS) (1). Immunohistochemistry plays an important role in the identification and diagnosis of SS (3). EMA and CD99 are the commonly used markers for diagnosis of epithelial and mesenchymal tumors, recently, they have also been used in the diagnosis of SS. Approximately $60 \%$ of CD99 expression was positive and may be related to the histological type of SS. Most of the studies reported that CD99 showed high levels of expression 
in single phase synovial sarcoma and poorly differentiated synovial sarcoma. The positive expression rate of CD99 in the poorly differentiated SS was $>90 \%$ (2).

The cellular origin of SS remains unknown, SS is currently classified as a miscellaneous tumor of uncertain histological origin, which is considered to arise from undifferentiated mesenchymal cells (2). Studies have supported the histogenesis and initiation of tumor may involve cancer stemlike cells (CSLCs) that may derive from a small population of pluripotent stem cells (4-6). These stem-like cells initiate and sustain tumor growth in epithelial tumors including various soft tissue sarcoma such as synovial sarcoma (7-12). Specific surface markers such as CD133, CD44 and nestin have been identified to isolate the cancer stem cells in breast cancer, pancreatic cancer and gastric cancer (13-15). However, the relationship between SS and tumor stem cells are still poorly understood. Studies have indicated that CD133 and other tumor stem cell-related markers are highly expressed in SS. The identification of cancer stem cell marker expression level has contributed to the understanding of the pathogenesis and origin of SS, and provides a new perspective for the diagnosis and treatment of SS.

Recent studies showed that $>90 \%$ of synovial sarcoma with chromosomal translocation $\mathrm{t}(\mathrm{X} ; 18)(\mathrm{p} 11.2 ; \mathrm{q} 11.2)$ leads to formation of SYT-SSX fusion protein (16). It is generally believed that the SYT-SSX fusion gene is an important event in the early stage of synovial sarcoma. SYT-SSX is thought to be responsible for sarcoma initiation and development. The value of SYT-SSX fusion gene in the diagnosis of synovial sarcoma has been widely recognized, however, the mechanism remains elusive (17).

This study explored immunohistochemical expression level of stem cell-associated markers to determine the possible histogenesis and pathogenesis of SS. Fusion gene SYT-SSX was evaluated to assess diagnostic value and the molecular pathological features.

\section{Materials and methods}

Patients and tissue specimens. A total of 20 SS patients were included from the Department of Pathology, the First Affiliated Hospital, Shihezi University School of Medicine between 1978 and 2016. Histopathological diagnosis was evaluated independently by two certified pathologists from the Department of Pathology, the First Affiliated Hospital, Shihezi University School of Medicine. The collected data included age, gender, sites, tumor size, histological type, tumor stage, molecular pathology, metastases, and the follow-up surveys (Table I). The study was approved by the institutional ethics committee at the First Affiliated Hospital of Shihezi University School of Medicine. Consent was obtained from the subjects for participation in the study and the use of their tissue.

Immunohistochemistry. Sections $(4 \mu \mathrm{m})$ prepared from formalin-fixed and paraffin-embedded tissue were obtained for immunohistochemical analysis. EnVisions two-step immunohistochemical kit (EnVision; Dako, Glostrup, Denmark) were used to detect specific target proteins. Briefly, the baked sections were deparaffinized with xylene and rehydrated in graded ethanol. Then sections were performed by microwave in citrate buffer ( $\mathrm{pH} 6.0)$, heated at $100^{\circ} \mathrm{C}$ and quenched with $3 \%$ hydrogen peroxide. The samples were incubated with specific target antibodies at $4^{\circ} \mathrm{C}$ overnight. The information of stem cell markers (including CD133, CD29, CD44, nestin and ALDH1) are shown in Table II. Sections were then washed with PBS and incubated with secondary antibodies at $37^{\circ} \mathrm{C}$. 3, 3'-Diaminobenzidine (DAB) was used as a chromogen. Finally, slides were counterstained with hematoxylin, gradient alcohol and xylene dehydration, and mounted. The expression of stem cell markers was scored semi-quantitatively according to the percentage of positive cells and staining intensity. The samples were scored according to the staining intensity and the ratio of positive cells as follows: distribution $(0,0 \% ; 1$, $\leq 10 \% ; 2,10-50 \% ; 3, \geq 50 \%)$ and intensity $(0$, negative; 1 , weak; 2 , moderate; and 3 , strong). A score of 0 was given for sections with no staining, and 1 was the lowest positive score. The product of the two scores determined the final score values; a score of 0 indicated negative expression (-), whereas a score of 1-3 represented weak positive expression (+). Similarly, a score of 4-12 was considered as strong positive expression (++). All of the results were confirmed by at least two senior pathologists independently.

Reverse transcription polymerase chain reaction (RT-PCR). Total RNA was extracted from 18 of 20 paraffin-embedded tissues of SS using TRIzol, the other 2 cases were from consultations which did not provide paraffin tissue. Since 2 of 18 paraffin tissues could not be evaluated by RT-PCR because of the low RNA quality, 16 cases of RNA were successfully tested. To detect SYT-SSX transcript and positive control $\beta$-actin transcript, the design of the primers is shown in Table III. One-step RT-PCR was conducted using RNA PCR kit. The PCR products were visualized by electrophoresis on $2 \%$ agarose gels.

Statistical analysis. Data were analyzed by SPSS software 17.0, and Fisher exact test was used to compare the relationship between the stem cell associated markers expression and clinicopathological data. Two-tailed P-values at $<0.05$ were considered statistically significant.

\section{Results}

Clinical findings. The SS patients comprised of 10 males and 10 females, with a median age of 37 years (range: 10-64 years). All samples were primary tumors located in the limbs (17 cases) and extra-limb (oral, kidney, and neck). According to the follow-up survey, 7 patients had a poor prognosis with distant metastases (5 patients with lung metastasis, 1 patient with liver metastasis, and 1 patient with bone metastasis). Three patients still live with disease after presentation. Three patients dropped out, the other 14 patients died of their disease (Table I). ALDH1- SS cases had good prognosis with higher survival rate than ALDH1 ${ }^{+}$SS cases $(\mathrm{P}<0.05)$ (Fig. 1, Table IV).

Pathological findings. According to the fourth WHO diagnostic criteria SS can be divided into biphasic synovial sarcoma (BSS), monophasic fibrous synovial sarcoma (MFSS) and poorly differentiated synovial sarcoma (PDSS). Histologically, the main characteristic of synovial sarcoma is 
Table I. Clinical data in 20 cases of synovial sarcomas.

\begin{tabular}{|c|c|c|c|c|c|c|c|c|}
\hline Patient ID & Gender/Age & Site & Size $(\mathrm{cm})$ & Diagnosis & TNM & Fusion gene & Metastases & Outcome \\
\hline 1 & $\mathrm{M} / 14$ & $\begin{array}{l}\text { Left elbow } \\
\text { fossa }\end{array}$ & 6 & MFSS & IIB & SYT-SSX2 & NM & DOD \\
\hline 2 & $\mathrm{~F} / 19$ & Left thigh & 7.5 & MFSS & III & SYT-SSX & NM & NA \\
\hline 3 & $\mathrm{M} / 32$ & Oral & 3 & MFSS & I & SYT-SSX1 & Lung & DOD \\
\hline 4 & $\mathrm{M} / 37$ & Right elbow & 2 & MFSS & III & SYT-SSX2 & NM & DOD \\
\hline 5 & $\mathrm{M} / 40$ & Left hip & 22 & MFSS & IV & SYT-SSX2 & Liver & Alive \\
\hline 6 & $\mathrm{M} / 47$ & Left leg & 5 & MFSS & IV & SYT-SSX2 & Lung & DOD \\
\hline 7 & $\mathrm{~F} / 40$ & Left bone & 7.5 & PDSS & III & SYT-SSX & NM & DOD \\
\hline 8 & $\mathrm{~F} / 10$ & Right elbow & 5 & BSS & IV & SYT-SSX1 & $\begin{array}{l}\text { Bone marrow } \\
\text { cavity }\end{array}$ & DOD \\
\hline 9 & $\mathrm{~F} / 15$ & Right neck & 4 & BSS & IIA & NA & NM & NA \\
\hline 10 & $F / 21$ & Right thigh & 7.5 & BSS & I & SYT-SSX1 & NM & Alive \\
\hline 11 & $F / 22$ & Left heel & 3 & BSS & IIA & SYT-SSX1 & NM & NA \\
\hline 12 & $F / 32$ & Left groin & NA & BSS & IIA & NA & NM & DOD \\
\hline 13 & $\mathrm{M} / 36$ & Left forearm & 11 & BSS & III & SYT-SSX1 & NM & DOD \\
\hline 14 & $\mathrm{~F} / 37$ & $\begin{array}{l}\text { Left hand and } \\
\text { forearm }\end{array}$ & 6 & BSS & III & SYT-SSX1 & NM & DOD \\
\hline 15 & $\mathrm{M} / 40$ & Right femoral & 2.8 & BSS & IV & SYT-SSX1 & NM & DOD \\
\hline 16 & $\mathrm{~F} / 43$ & Right kidney & 13 & BSS & III & SYT-SSX1 & NM & DOD \\
\hline 17 & $\mathrm{M} / 52$ & Left ilium & 5 & BSS & III & SYT-SSX2 & NM & Alive \\
\hline 18 & $\mathrm{~F} / 55$ & Right foot & 10 & BSS & IV & SYT-SSX1 & Lung & DOD \\
\hline 19 & $\mathrm{M} / 55$ & Left thigh & 5.2 & BSS & I & SYT-SSX1 & Lung & DOD \\
\hline 20 & $\mathrm{M} / 64$ & Left hip & 11.5 & BSS & IV & SYT-SSX1 & Lung & DOD \\
\hline
\end{tabular}

BSS, biphasic synovial sarcoma; MFSS, monophasic fibrous synovial sarcoma; PDSS, poorly differentiated synovial sarcoma; F, female; M, male; NM, not metastasizing; DOD, died of disease; NA, not available.

Table II. Primary antibodies used in the immunohistochemistry staining.

\begin{tabular}{|c|c|c|c|c|c|}
\hline Antigen & Antibody species & Location & Company & Clone number & Dilution \\
\hline CD133 & Rabbit Polyclonal & Cytoplasm & ARP, Waltham, MA, USA & 05-PA1021 & $1: 200$ \\
\hline CD29 & Rabbit monoclonal & Cytoplasm & Abcam, Cambridge, UK & EP1041Y & $1: 800$ \\
\hline CD44 & Mouse monoclonal & Cytomembrane & Dako, Glostrup, Denmark & DF1485 & $1: 300$ \\
\hline Nestin & Rabbit monoclonal & Cytoplasm & Abcam, Cambridge, UK & SP103 & $1: 200$ \\
\hline ALDH1 & Rabbit monoclonal & Cytoplasm & Abcam, Cambridge, UK & EP1933Y & $1: 200$ \\
\hline
\end{tabular}

Table III. The primers of SYT-SSX and $\beta$-actin.

\begin{tabular}{lc}
\hline Primer & \multicolumn{1}{c}{ Sequence } \\
\hline SYT & 5'-CCAGCAGAGGCCTTATGGATA-3' \\
SSX & 5'-TTTGTGGGCCAGATGCTTC-3' \\
SSX1 & 5'-GTGCAGTTGTTTCCCATCG-3' \\
SSX2 & 5'-GCACAGCTCTTTCCCATCA-3' \\
$\beta$-actin-F & 5'-CAGTTTGGAGCTCCTGGAAG-3' \\
$\beta$-actin-R & 5'-TGCAAATCCAGGGTGCAGTG-3' \\
\hline
\end{tabular}

epithelial and mesenchymal biphasic differentiation. In our study, the median tumor size was $7.2 \mathrm{~cm}$, with a range from 2 to $22 \mathrm{~cm}$. The cases were composed of 13 biphasic synovial sarcoma (BSS), 6 monophasic fibrous synovial sarcoma (MFSS), and 1 poorly differentiated synovial sarcoma (PDSS). Biphasic SS contained epithelial cells and spindle cells. The variable biphasic differentiation presented glands with a tubular or papillary architecture or solid nests with a population of oval or rounded cells. Epithelioid cells formed glands. Glands are irregular and covered by columnar or cuboidal cells. Tumor cells had eosinophilic cytoplasm, nucleus was round or oval and hyperchromatic (Fig. 2A and B). The spindle 
A

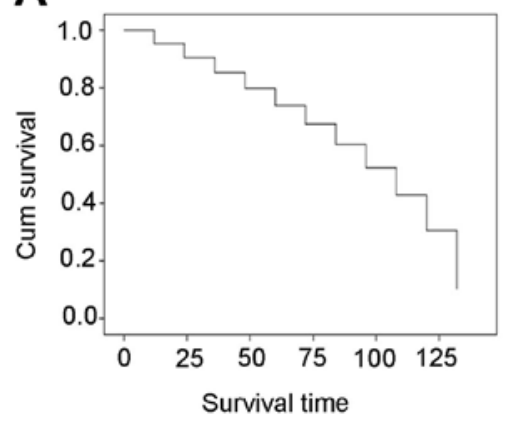

B

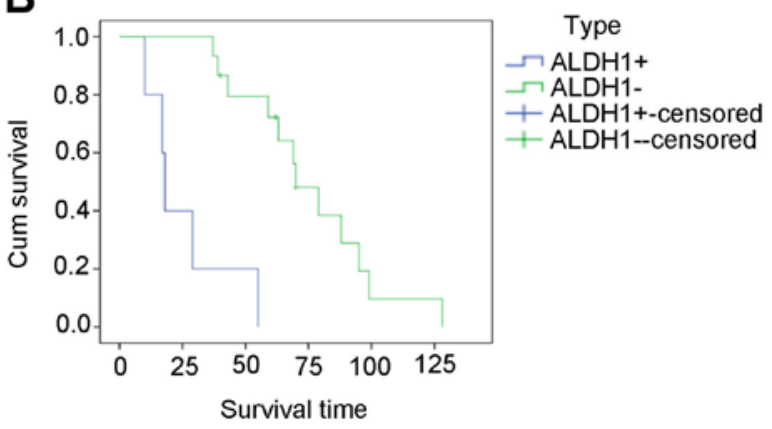

Figure 1. The cumulative survival rate of all synovial sarcoma patients. All patients died at follow-up in 128 months, excepting lost to follow-up patients (A). The cumulative survival rate of ALDH1+ and ALDH1- synovial sarcoma patients. Patients who ALDH1-positive had a worse event-free survival than patients ALDH1-negative (B).
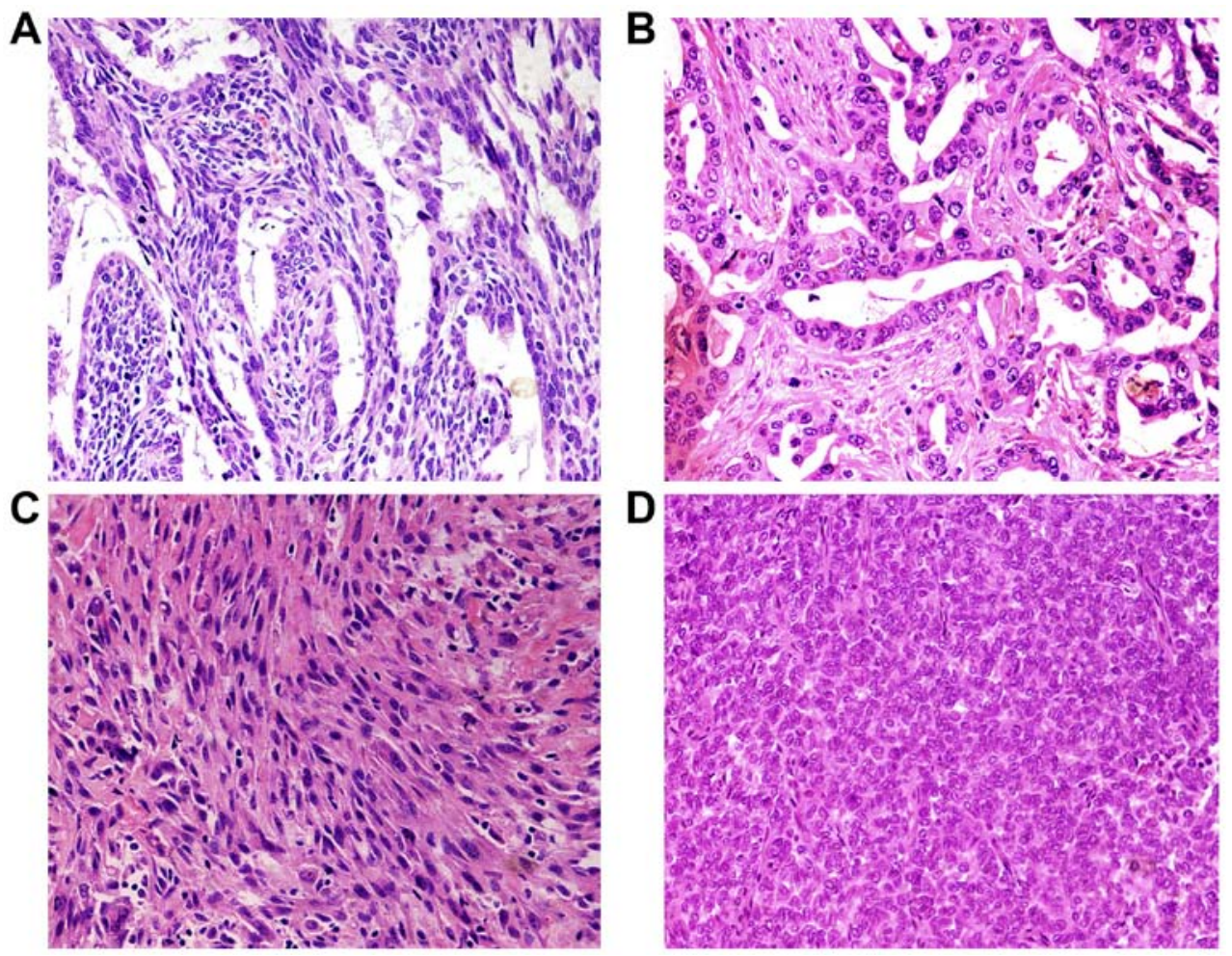

Figure 2. Histologic features of synovial sarcoma (SS). SS displaying biphasic type synovial sarcoma (BSS) of glandular structure (A, x200) or solid nests (B, x200). MFSS composed of highly cellular short fascicles of uniform spindle cells (C, x200). PDSS composed of round tumor cells with nuclear atypia (D, $\mathrm{x} 200)$.

Table IV. P-value of the cumulate survival of ALDH1 ${ }^{+}$and ALDH1 synovial sarcoma patients.

\begin{tabular}{lccc}
\hline & \multicolumn{3}{c}{ Overall comparisons } \\
\cline { 2 - 5 } Test & Chi-square & df & Sig \\
\hline Log Rank (Mantel-Cox) & 18.190 & 1 & $<0.001$ \\
\hline
\end{tabular}

Test of survival distributions for the different level of type.

cells resemble histologically the monophasic fibrous synovial sarcoma and were ovoid to uniform spindle-shaped with elongated nuclear features forming dense cellular sheets and fascicles. The cell atypia was inconspicuous with pale-stained or eosinophilic cytoplasm. Nucleus showed short spindle shape, granular chromatin, mesenchymal vascular slightly enriched, slit-shaped thin wall (Fig. 2C). Poorly differentiated type synovial sarcoma was composed of round hyperchromatic atypical tumor cells with diffuse distribution. The cell nucleus was large, obviously atypical and eosinophilic (Fig. 2D).

Immunohistochemical findings of stem cell marker expression in SS. In 20 specimens, 17 were stained positive for CD133, 11 of 20 were positive for CD29 and CD44, 6 of 20 were positive for nestin (Tables V and VI). CD133 was detected in epithelial cells (Figs. 3A and B, and 4A and B). CD29 were also detected in the vascular endothelial cells 

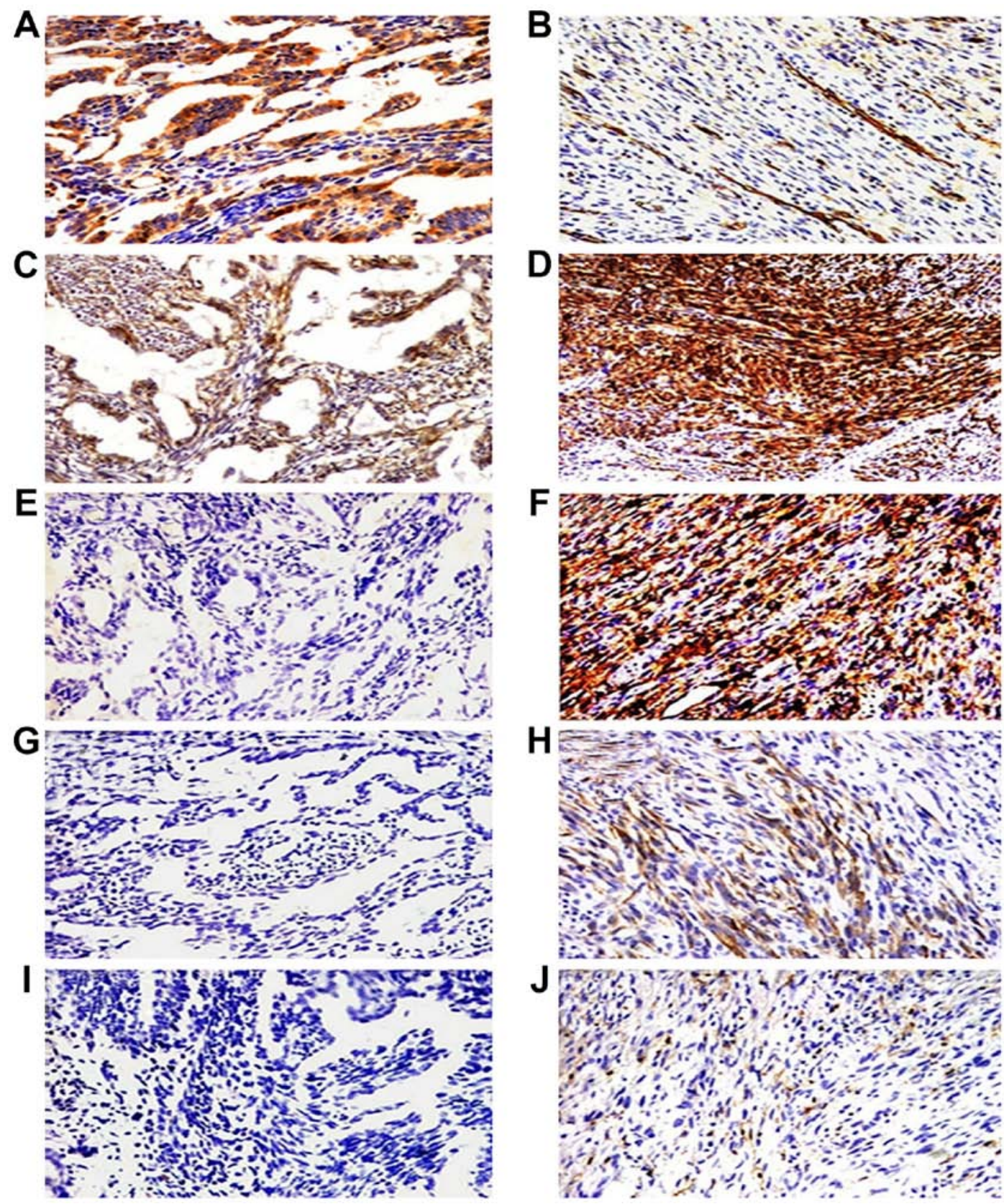

Figure 3. Immunohistochemical staining of the five cancer stem marker expression including CD133, CD29, CD44, nestin and ALDH1 in epithelial cells and spindle cells of biphasic type synovial sarcoma (BSS). Epithelial cells of BSS positive expression for CD133 and CD29 (A and C, x200) and negative expression for CD44, nestin and ALDH1 (E, G and I, x200). Spindle cells of BSS overexpressed CD29 and CD44 (D and F, x400), scattered expression of CD133, nestin and ALDH1 (B, H and J, x400).

(Figs. 3C and D, and 4C and D). CD44 and nestin displayed focal immunoreactivity in spindle cells (Figs. 3E-H; 4E-H). Of the 20 specimens, 5 were ALDH1-positive in scattered tumor cells (Figs. 3J and 4J) and negative in 15 cases (Figs. 3I and $4 \mathrm{I}$ ). There was no statistically significant relationship between the expression of stem cell-associated markers (CD133, CD29, CD44, nestin, and ALDH1) and clinical data (age, gender, sites, tumor size, histological type, tumor stage, and metastases) ( $\mathrm{P}>0.05)$, the expression of ALDH1 was significantly related to the metastases of SS $(\mathrm{P}<0.05)$ (Tables VII and VIII).

$R T-P C R$. Total RNA was extracted and evaluated successfully from 18 cases of SS. The $\beta$-actin was tested in $247 \mathrm{bp}$. The results of RT-PCR showed that fusion gene SYT-SSX (98 bp) was available in all the cases, SYT-SSX1 and SYT-SSX2 fusion gene were tested in $118 \mathrm{bp}$. SYT-SSX1 and SYT-SSX2 transcript were detected in 11 cases and 5 cases respectively. Among 11 cases of SYT-SSX1, 10 cases were BSS and 1 case was MFSS, the 5 cases of SYT-SSX2 included 4 cases of MFSS and 1 case of BSS. Two cases showed no explicit typing (Table I; Figs. 5 and 6).

\section{Discussion}

Synovial sarcoma (SS) is classified as uncertain differentiation tumor in the 4th WHO Classification of soft tissue tumors that occur in a widely variety of organs, especially near the joints 

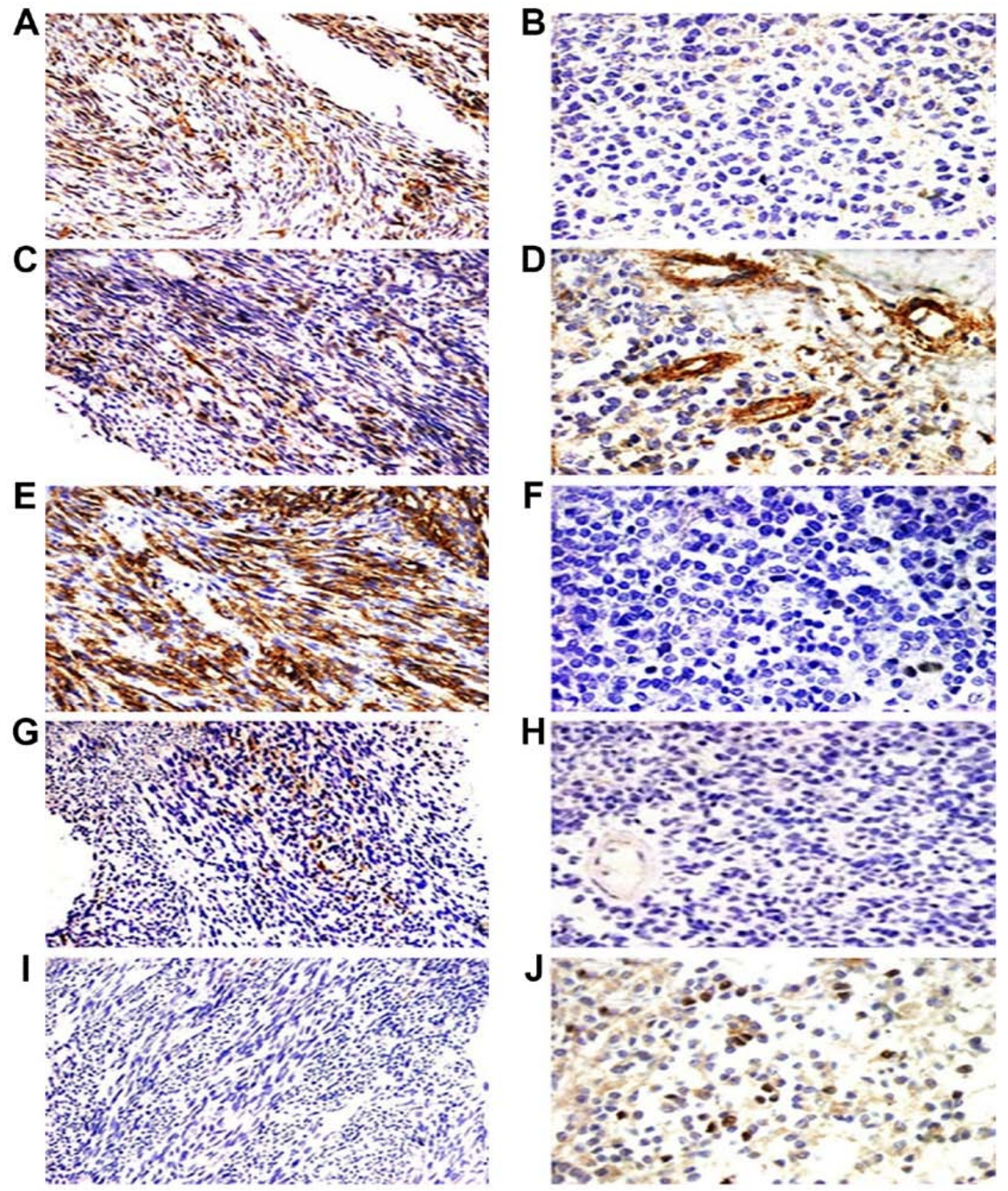

Figure 4. Immunohistochemical staining of the five cancer stem marker expression including CD133, CD29, CD44, nestin and ALDH1 in monophasic fibrous synovial sarcoma (MFSS) and poorly differential synovial sarcoma (PDSS). MFSS positive expression of CD133, CD29 and CD44 (A, C and E, x200) and scattered expression of ALDH1 (J, x200), scattered expressed of nestin (G, x200), negative expression of CD133, CD44 and nestin (B, F, and H, x400). PDSS scattered expression of CD29 and ALDH1 (D and J, x400), and with positive expression of CD29 in vascular (D, x400), negative expression of ALDH1 (I, x200).

of the limbs. SS occurs more frequently in young adults, in males more common than females. SS is a highly malignant soft tissue tumor with poor prognosis, the recurrence rate was approximately $50 \%$ within two years after operation and metastasis occurred in $40 \%$ of patients. The 5 -year survival rate was $<30 \%$, lung and lymph node metastasis may be negative prognostic factors of long-term survival. Thus, confirming the tumor cellular and tissue origin is of great significance in the process of making a correct diagnosis and differential diagnosis of SS $(1,16,17)$.

In the present study, distant metastasis occurred in 7 patients, in addition to 3 patients lost to follow-up and 3 patients still alive, the other 14 patients all died of a tumor. Recent studies supported that cancer is initiated by a popula- tion of tumor cells with stem cell characteristics (18-20). The cancer stem cell hypothesis suggests that cancer stem cells may contribute to the initiation, progression and recurrence of cancer $(21,22)$. Expression of cancer stem cell makers have been reported in leukemia, breast cancer, colon cancer and sarcoma $(7,8,10,11,23,24)$. CD133 was first described as a surface antigen specific to human hematopoietic stem and progenitor cells, but has also recently been recognized as a common stem cell marker (14,25-28). CD133 may be responsible for tumorigenesis and represents a pool of tumor progenitor cells or tumor stem cells (12). Terry et al isolated a small amount of $\mathrm{CD}_{133^{+}}$cells from SS cell line for the first time, this suggested the relationship between SS and cancer stem-like cells (25). 


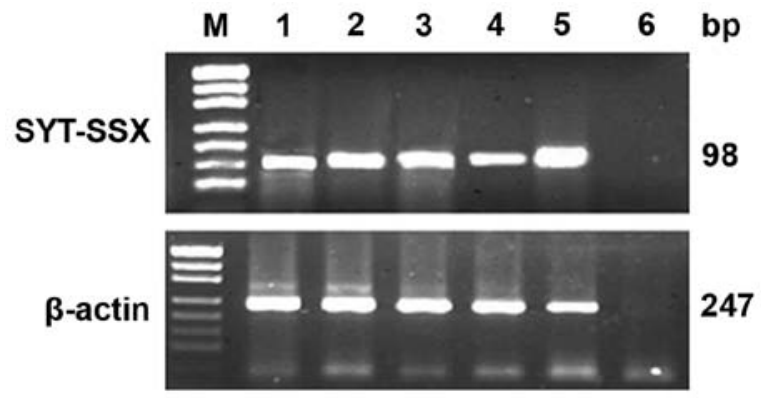

Figure 5. Bio-Rad gel image of SYT-SSX and $\beta$-actin. Lanes 1-5, positive for SYT-SSX in 98 bp and $\beta$-actin in 247 bp; lane 6, blank control.

Table V. Immunohistochemical expression for 5 stem cell markers in synovial sarcoma.

\begin{tabular}{|c|c|c|c|c|c|}
\hline \multirow{2}{*}{$\begin{array}{l}\text { Patient } \\
\text { ID }\end{array}$} & \multicolumn{5}{|c|}{ Stem cell markers } \\
\hline & CD133 & CD29 & CD44 & Nestin & ALDH1 \\
\hline 1 & ++ & - & ++ & - & - \\
\hline 2 & + & - & + & - & - \\
\hline 3 & + & - & ++ & - & - \\
\hline 4 & + & + & + & + & - \\
\hline 5 & ++ & + & + & - & - \\
\hline 6 & + & - & - & - & + \\
\hline 7 & - & - & - & - & + \\
\hline 8 & ++ & - & - & - & + \\
\hline 9 & ++ & ++ & - & - & - \\
\hline 10 & ++ & ++ & + & - & - \\
\hline 11 & + & + & - & - & - \\
\hline 12 & + & ++ & - & - & - \\
\hline 13 & - & ++ & ++ & + & - \\
\hline 14 & ++ & + & ++ & - & - \\
\hline 15 & + & - & - & - & - \\
\hline 16 & - & ++ & ++ & - & - \\
\hline 17 & ++ & ++ & ++ & + & + \\
\hline 18 & ++ & - & - & + & - \\
\hline 19 & ++ & - & - & ++ & - \\
\hline 20 & + & ++ & ++ & ++ & + \\
\hline
\end{tabular}

-, negative; +, weak positive; ++, positive.

In our immunohistochemical study, CD133 was positively expressed in $85 \%$ SS cases. It implies SS may be derived from stem cells and progenitor cells. ALDH1 has been considered to be cancer stem cell marker in lung cancer, liver cancer, colon cancer, prostate cancer, and breast cancer. Recently, some evidence proved that ALDH1 staining was observed as stem cell marker in soft tissue tumors, such as solitary fibrous tumor $(29,30)$. Bouvier et al (29) reported that ALDH1 expression may play an important role in distinguishing SS from soft tissue tumors such as solitary fibrous tumors. Many studies have found that the expression of ALDH1 protein is related to the histologic subtypes, recurrence, metastasis and invasion of

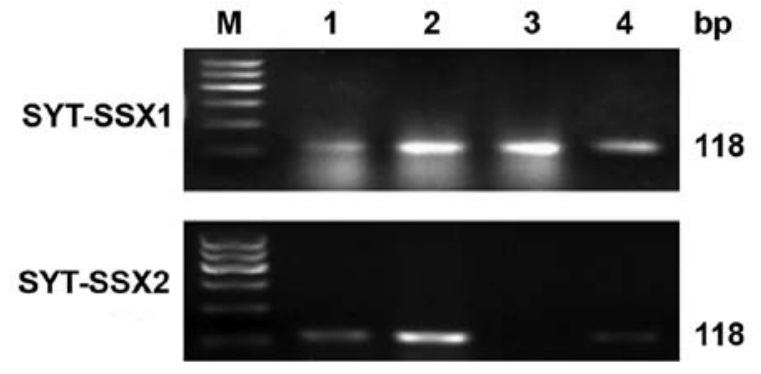

Figure 6. Bio-Rad gel image of SYT-SSX1 and SYT-SSX1: positive for SYT-SSX1 and SYT-SSX2 in 118 bp.

Table VI. Five stem cell marker expression in synovial sarcoma.

\begin{tabular}{lcccc}
\hline Markers & $\begin{array}{c}\text { Negative } \\
(-)\end{array}$ & $\begin{array}{c}c \\
\end{array}$ & $\begin{array}{l}\text { Positive } \\
(+)\end{array}$ & $\begin{array}{c}\text { Positive rate }(\%)^{\mathrm{a}} \\
(\mathrm{n})\end{array}$ \\
\hline CD133 & 3 & 9 & 8 & $85(17)$ \\
CD29 & 9 & 4 & 7 & $55(11)$ \\
CD44 & 9 & 4 & 7 & $55(11)$ \\
Nestin & 14 & 4 & 2 & $30(6)$ \\
ALDH1 & 15 & 4 & 1 & $25(5)$ \\
\hline
\end{tabular}

${ }^{a}$ Included all weak positive $(+)$ and positive $(++)$. Positive expression: CD133 (17/20), CD29 (11/20), CD44 (11/20), nestin (6/20) and ALDH1 (5/20).

the tumor. Increasing evidence has demonstrated ALDH1 as therapeutic target and a malignant tumor stem cell marker that indicates poor prognosis for tumors, decreased ALDH1 may suggest a good prognosis $(31,32)$.

In our study, only 5 cases were positive for ALDH1, while ALDH1-positive cases are characteristic of poorly differentiated, tumors $\geq 5 \mathrm{~cm}$, and TNM III/IV, especially in metastases. $\mathrm{ALDH}^{-} \mathrm{SS}$ cases had better survival rate than $\mathrm{ALDH} 1^{+} \mathrm{SS}$ cases. This suggested that the SS may originate from cancer stem like cells. The high expression of ALDH1 may suggest an immature undifferentiated state and high malignancy, which leads to poor prognosis. The high expression of ALDH1 may be responsible for the failure of traditional chemotherapy of some malignancies including colon cancer (33), prostate cancer (34) and breast cancer (35).

More studies need to be done to explore the role of ALDH1 in the development of SS. SS occur in multiple sites of the body, the cellular origin may be cells with multiple differentiation ability, such as stem cells. Studies show high expression of MSC surface markers in SS. CD29, nestin, and CD44 are surface proteins associated with mesenchymal stem cells (MSCs) $(14,15,36)$. MSC markers CD29 and CD44 displayed high expression (55\%). The mesenchymal stem/ progenitor cells markers CD29 or CD44 could be identified and separated from SS, this suggested that SS may originate from mesenchymal stem/progenitor cells (37). Recently, nestin was considered as a stem cell or progenitor cell surface marker. Nestin was detected in 6 SS cases in this investiga- 
Table VII. Association between expression of 5 stem cell markers, fusion gene and clinicopathological features.

\begin{tabular}{|c|c|c|c|c|c|c|c|c|c|c|c|c|}
\hline \multirow[b]{2}{*}{ Factors } & \multicolumn{2}{|c|}{ CD133 } & \multirow[b]{2}{*}{$\chi^{2}$ value } & \multirow[b]{2}{*}{ P-value } & \multicolumn{2}{|c|}{$\mathrm{CD} 29$} & \multirow[b]{2}{*}{$\chi^{2}$ value } & \multirow[b]{2}{*}{ P-value } & \multicolumn{2}{|c|}{ CD44 } & \multirow[b]{2}{*}{$\chi^{2}$ value } & \multirow[b]{2}{*}{$\mathrm{P}$-value } \\
\hline & Negative & Positive & & & Negative & Positive & & & Negative & Positive & & \\
\hline Age & & & 0.131 & $>0.05$ & & & 0.067 & $>0.05$ & & & 0.067 & $>0.05$ \\
\hline$<50$ & 2 & 13 & & & 7 & 8 & & & 7 & 8 & & \\
\hline$\geq 50$ & 1 & 4 & & & 2 & 3 & & & 2 & 3 & & \\
\hline Gender & & & 0.392 & $>0.05$ & & & 1.181 & $>0.05$ & & & 0.202 & $>0.05$ \\
\hline $\mathrm{F}$ & 2 & 8 & & & 3 & 7 & & & 5 & 5 & & \\
\hline M & 1 & 9 & & & 6 & 4 & & & 4 & 6 & & \\
\hline Size $(\mathrm{cm})$ & & & 1.644 & $>0.05$ & & & 0.024 & $>0.05$ & & & 2.170 & $>0.05$ \\
\hline$<5$ & 0 & 6 & & & 3 & 3 & & & 4 & 2 & & \\
\hline$\geq 5$ & 3 & 10 & & & 6 & 7 & & & 4 & 9 & & \\
\hline TNM & & & 0.669 & $>0.05$ & & & 0.900 & $>0.05$ & & & 3.104 & $>0.05$ \\
\hline $\mathrm{I}, \mathrm{II}$ & 1 & 10 & & & 3 & 6 & & & 3 & 8 & & \\
\hline III, IV & 2 & 7 & & & 6 & 5 & & & 6 & 3 & & \\
\hline Metastases & & & 1.900 & $>0.05$ & & & 0.642 & $>0.05$ & & & 0.020 & $>0.05$ \\
\hline+ & 0 & 7 & & & 4 & 3 & & & 3 & 4 & & \\
\hline- & 3 & 10 & & & 5 & 8 & & & 6 & 7 & & \\
\hline Fusion gene & & & 1.039 & $>0.05$ & & & 0.042 & $>0.05$ & & & 0.95 & $>0.05$ \\
\hline SYT-SSX1 & 2 & 9 & & & 5 & 6 & & & 5 & 6 & & \\
\hline SYT-SSX2 & 0 & 5 & & & 2 & 3 & & & 1 & 4 & & \\
\hline Histology & & & 1.644 & $>0.05$ & & & 1.310 & $>0.05$ & & & 2.328 & $>0.05$ \\
\hline MFSS & 0 & 6 & & & 4 & 2 & & & 1 & 5 & & \\
\hline BSS & 3 & 10 & & & 5 & 8 & & & 7 & 6 & & \\
\hline
\end{tabular}

BSS, biphasic synovial sarcoma; MFSS, monophasic fibrous synovial sarcoma; PDSS, poorly differentiated synovial sarcoma.

tion, it was positive in MFSS or spindle cells of BSS in our study. This suggested spindle cells of SS may originate from MSCs. However, the relationship between stem cells and SS is poorly understood, a larger number of SS patients needs to be explored for the histogenesis of SS.

$\mathrm{SS}$ is characterized by a chromosomal translocation $\mathrm{t}(\mathrm{X} ; 18)$ (p11.2;q11.2), and this molecular genetic feature does not appear in other tumors (38-40). SYT-SSX was tested positive in $93 \%$ cases of SS. The function of SYT-SSX fusion protein is not clear, but Naka et al reported that SS may be a stem cell malignancy because of the dysregulation of self-renewal and differentiation driven by SYT-SSX fusion protein (37). Garcia et al (41) reported that mesenchymal stem cells may be reprogrammed by SS-associated protein SYT-SSX, the aberrant differentiation of human mesenchymal stem cells were caused by SYT-SSX2. However, more studies need to be done to explore the relationship between stem cells and SYT-SSX fusion gene. Saito (42) reported that the tumor phenotype may be determined by the SYT-SSX fusion gene. Our study showed that $77 \%$ of BSS had the SYT-SSX1 fusion gene (10/13) and 67\% MFSS the SYT-SSX2 fusion gene (4/6). SYT-SSX can be used as an excellent diagnostic marker for SS. In our study, SYT-SSX was detected in 18 cases, of these, 7 had distant metastasis (1 case metastasis to bone, 1 case metastasis to liver, 5 cases metastasis to lung), 14 patients died of the disease ( 3 patients were not available, 3 patients are still alive). SYT-SSX1 may be related to the high proliferation rate of tumor cells, tumor distant metastasis and poor prognosis (38-40). SYT-SSX1 fusion gene was detected in $71.4 \%$ $(5 / 7)$ of cases of SS with distant metastasis. Gene therapy for SYT-SSX will be of great importance for the diagnostics, treatment and prognosis of SS.

In conclusion, we detected stem cell marker (CD133, CD29, CD44, nestin, and ALDH1) expression to explore the histogenesis and cellular origin of SS. The immunohistochemical findings for the stem cell markers indicated that SS may originate from MSCs. The RT-PCR results showed fusion gene SYT-SSX may play an important role in the tumor initiation and progression of SS. Due to the characteristic expression of stem cell markers and SYT-SSX for $\mathrm{SS}$, these may provide new efficient drug design and therapy strategy in future. Our results need to be confirmed by further exploration to study the function of cancer stem cell markers and fusion gene SYT-SSX for histogenesis and pathogenesis of SS.

\section{Acknowledgements}

This work was supported by National Natural Science Foundation of China (no. 81560053), the Corps Doctor 
Table VIII. Association between expression of 5 stem cell markers and clinicopathological features.

\begin{tabular}{|c|c|c|c|c|c|c|c|c|c|c|c|c|}
\hline \multirow[b]{2}{*}{ Factors } & \multicolumn{2}{|c|}{ Nestin } & \multirow[b]{2}{*}{$\chi^{2}$ value } & \multirow[b]{2}{*}{$\mathrm{P}$-value } & \multicolumn{2}{|c|}{ ALDH1 } & \multirow[b]{2}{*}{$\chi^{2}$ value } & \multirow[b]{2}{*}{ P-value } & \multicolumn{2}{|c|}{ Fusion gene } & \multirow[b]{2}{*}{$\chi^{2}$ value } & \multirow[b]{2}{*}{ P-value } \\
\hline & Negative & Positive & & & Negative & Positive & & & $\begin{array}{l}\text { SYT- } \\
\text { SSX1 }\end{array}$ & $\begin{array}{l}\text { SYT- } \\
\text { SSX2 }\end{array}$ & & \\
\hline Age & & & 2.260 & $>0.05$ & & & 0.800 & $>0.05$ & & & 0.097 & $>0.05$ \\
\hline$<50$ & 13 & 4 & & & 12 & 3 & & & 8 & 4 & & \\
\hline$\geq 50$ & 1 & 2 & & & 3 & 2 & & & 3 & 1 & & \\
\hline Gender & & & 0.952 & $>0.05$ & & & 0.267 & $>0.05$ & & & 4.364 & $>0.05$ \\
\hline $\mathrm{F}$ & 8 & 2 & & & 7 & 3 & & & 6 & 0 & & \\
\hline M & 6 & 4 & & & 8 & 2 & & & 5 & 5 & & \\
\hline Size $(\mathrm{cm})$ & & & 0.012 & $>0.05$ & & & 3.132 & $>0.05$ & & & 0.097 & $>0.05$ \\
\hline$<5$ & 4 & 2 & & & 6 & 0 & & & 3 & 1 & & \\
\hline$\geq 5$ & 9 & 4 & & & 8 & 5 & & & 8 & 4 & & \\
\hline TNM & & & 0.087 & $>0.05$ & & & 0 & $>0.05$ & & & 0.428 & $>0.05$ \\
\hline I, II & 8 & 3 & & & 9 & 3 & & & 4 & 1 & & \\
\hline III, IV & 6 & 3 & & & 6 & 2 & & & 7 & 4 & & \\
\hline Metastases & & & 0.848 & $>0.05$ & & & 12.381 & 0.001 & & & 0.042 & $>0.05$ \\
\hline+ & 4 & 3 & & & 13 & 0 & & & 5 & 2 & & \\
\hline- & 10 & 3 & & & 2 & 5 & & & 6 & 3 & & \\
\hline Fusion gene & & & 0.019 & $>0.05$ & & & 0.873 & $>0.05$ & & & - & - \\
\hline SYT-SSX1 & 7 & 4 & & & 9 & 2 & & & - & - & & \\
\hline SYT-SSX2 & 3 & 2 & & & 3 & 2 & & & & & & \\
\hline Histology & & & 0.903 & $>0.05$ & & & 3.041 & $>0.05$ & & & 8.045 & 0.013 \\
\hline MFSS & 5 & 1 & & & 9 & 4 & & & 1 & 4 & & \\
\hline BSS & 8 & 5 & & & 8 & 0 & & & 10 & 1 & & \\
\hline
\end{tabular}

BSS, biphasic synovial sarcoma; MFSS, monophasic fibrous synovial sarcoma; PDSS, poorly differentiated synovial sarcoma.

Foundation (no. 2014BB018), Shihezi University Outstanding Youth Science and Technology Talent Cultivation Plan (2013ZRKXJQ05, 2015ZRKXJQ07), the Pairing Program of Shihezi University with Eminent Scholar in Elite University (SDJDZ201508), Research Project of High Level Talents of Shihezi University (RCZX201549).

\section{References}

1. Weiss SW and Goldblum JR (eds): Enzinger and Weiss's Soft Tissue Tumors. Vol. 30. 5th edition. Mosby Elsevier, Philadelphia, PA, 2008.

2. Fletcher CDM, Bridge JA, Hogendoorn P and Mertens F: WHO Classification of Tumours of Soft Tissue and Bone. 4th edition. IARC Press, 2013.

3. Haldar M, Hancock JD, Coffin CM, Lessnick SL and Capecchi MR: A conditional mouse model of synovial sarcoma: Insights into a myogenic origin. Cancer Cell 11: 375-388, 2007.

4. Lapidot T, Sirard C, Vormoor J, Murdoch B, Hoang T, CaceresCortes J, Minden M, Paterson B, Caligiuri MA and Dick JE: A cell initiating human acute myeloid leukaemia after transplantation into SCID mice. Nature 367: 645-648, 1994.

5. Hemmati HD, Nakano I, Lazareff JA, Masterman-Smith M, Geschwind DH, Bronner-Fraser M and Kornblum HI: Cancerous stem cells can arise from pediatric brain tumors. Proc Natl Acad Sci USA 100: 15178-15183, 2003.

6. Al-Hajj M, Wicha MS, Benito-Hernandez A, Morrison SJ and Clarke MF: Prospective identification of tumorigenic breast cancer cells. Proc Natl Acad Sci USA 100: 3983-3988, 2003.
7. Ponti D, Costa A, Zaffaroni N, Pratesi G, Petrangolini G, Coradini D, Pilotti S, Pierotti MA and Daidone MG: Isolation and in vitro propagation of tumorigenic breast cancer cells with stem/progenitor cell properties. Cancer Res 65: 5506-5511, 2005.

8. Chu P, Clanton DJ, Snipas TS, Lee J, Mitchell E, Nguyen ML, Hare E and Peach RJ: Characterization of a subpopulation of colon cancer cells with stem cell-like properties. Int J Cancer 124: 1312-1321, 2009.

9. Zeimet AG, Reimer D, Sopper S, Boesch M, Martowicz A, Roessler J, Wiedemair AM, Rumpold H, Untergasser G, Concin N, et al: Ovarian cancer stem cells. Neoplasma 59: 747-755, 2012.

10. Walter D, Satheesha S, Albrecht P,Bornhauser BC,D'Alessandro V, Oesch SM, Rehrauer H, Leuschner I, Koscielniak E, Gengler C, et al ; CWS Study Group: CD133 positive embryonal rhabdomyosarcoma stem-like cell population is enriched in rhabdospheres. PLoS One 6: e19506, 2011.

11. Mutsaers AJ and Walkley CR: Cells of origin in osteosarcoma: Mesenchymal stem cells or osteoblast committed cells? Bone 62: 56-63, 2014.

12. Liu A, Feng B, Gu W, Cheng X, Tong T, Zhang $\mathrm{H}$ and $\mathrm{Hu} \mathrm{Y}$ : The $\mathrm{CD}_{133^{+}}$subpopulation of the SW982 human synovial sarcoma cell line exhibits cancer stem-like characteristics. Int J Oncol 42: 1399-1407, 2013.

13. Kekarainen T, Mannelin S, Laine J and Jaatinen T: Optimization of immunomagnetic separation for cord blood-derived hematopoietic stem cells. BMC Cell Biol 7: 30, 2006.

14. Schieker M, Pautke C, Haasters F, Schieker J, Docheva D, Böcker W, Guelkan H, Neth P, Jochum M and Mutschler W: Human mesenchymal stem cells at the single-cell level: Simultaneous seven-colour immunofluorescence. J Anat 210: 592-599, 2007. 
15. Méndez-Ferrer S, Michurina TV, Ferraro F, Mazloom AR, Macarthur BD, Lira SA, Scadden DT, Ma'ayan A, Enikolopov GN and Frenette PS: Mesenchymal and haematopoietic stem cells form a unique bone marrow niche. Nature 466: 829-834, 2010.

16. Clark J, Rocques PJ, Crew AJ, Gill S, Shipley J, Chan AM, Gusterson BA and Cooper CS: Identification of novel genes, SYT and SSX, involved in the $\mathrm{t}(\mathrm{X} ; 18)(\mathrm{p} 11.2 ; \mathrm{q} 11.2)$ translocation found in human synovial sarcoma. Nat Genet 7: 502-508, 1994.

17. Ladanyi M: Fusions of the SYT and SSX genes in synovial sarcoma. Oncogene 20: 5755-5762, 2001

18. Boman BM and Wicha MS: Cancer stem cells: A step toward the cure. J Clin Oncol 26: 2795-2799, 2008.

19. Jung Y, Bauer G and Nolta JA: Concise review: Induced pluripotent stem cell-derived mesenchymal stem cells: progress toward safe clinical products. Stem Cells 30: 42-47, 2012.

20. Sadikovic B, Graham C, Ho M, Zielenska M and Somers GR Immunohistochemical expression and cluster analysis of mesenchymal and neural stem cell-associated proteins in pediatric soft tissue sarcomas. Pediatr Dev Pathol 14: 259-272, 2011.

21. Santagata S, Ligon KL and Hornick JL: Embryonic stem cell transcription factor signatures in the diagnosis of primary and metastatic germ cell tumors. Am J Surg Pathol 31: 836-845, 2007.

22. Ben-Porath I, Thomson MW, Carey VJ, Ge R, Bell GW, Regev A and Weinberg RA: An embryonic stem cell-like gene expression signature in poorly differentiated aggressive human tumors. Nat Genet 40: 499-507, 2008.

23. Passegué E: Hematopoietic stem cells, leukemic stem cells and chronic myelogenous leukemia. Cell Cycle 4: 266-268, 2005.

24. Nakanishi M, Niidome T, Matsuda S, Akaike A, Kihara T and Sugimoto H: Microglia-derived interleukin-6 and leukaemia inhibitory factor promote astrocytic differentiation of neural stem/progenitor cells. Eur J Neurosci 25: 649-658, 2007.

25. Terry J and Nielsen T: Expression of CD133 in synovial sarcoma. Appl Immunohistochem Mol Morphol 18: 159-165, 2010.

26. Collins AT, Berry PA, Hyde C, Stower MJ and Maitland NJ: Prospective identification of tumorigenic prostate cancer stem cells. Cancer Res 65: 10946-10951, 2005.

27. Okamoto H, Fujishima F, Nakamura Y, Zuguchi M, Ozawa Y, Takahashi Y, Miyata G, Kamei T, Nakano T, Taniyama Y, et al Significance of CD133 expression in esophageal squamous cell carcinoma. World J Surg Oncol 11: 51, 2013.

28. Zhang D, Sun B, Zhao X, Ma Y, Ji R, Gu Q, Dong X, Li J, Liu F, Jia $\mathrm{X}$, et al: Twist1 expression induced by sunitinib accelerates tumor cell vasculogenic mimicry by increasing the population of $\mathrm{CD}_{133^{+}}$cells in triple-negative breast cancer. Mol Cancer 13: 207, 2014.

29. Bouvier C, Bertucci F, Métellus P, Finetti P, Maues de Paula A, Forest F, Mokhtari K, Miquel C, Birnbaum D, Vasiljevic A, et al: ALDH1 is an immunohistochemical diagnostic marker for solitary fibrous tumours and haemangiopericytomas of the meninges emerging from gene profiling study. Acta Neuropathol Commun 1: 10, 2013.

30. England DM, Hochholzer L and McCarthy MJ: Localized benign and malignant fibrous tumors of the pleura. A clinicopathologic review of 223 cases. Am J Surg Pathol 13: 640-658, 1989.
31. Liu Y, Lv DL, Duan JJ, Xu SL, Zhang JF, Yang XJ, Zhang X, Cui YH, Bian XW and Yu SC: ALDH1A1 expression correlates with clinicopathologic features and poor prognosis of breast cancer patients: A systematic review and meta-analysis. BMC Cancer 14: 444, 2014.

32. Kuroda T, Hirohashi Y, Torigoe T, Yasuda K, Takahashi A, Asanuma H, Morita R, Mariya T, Asano T, Mizuuchi M, et al: ALDH1-high ovarian cancer stem-like cells can be isolated from serous and clear cell adenocarcinoma cells, and ALDH1 high expression is associated with poor prognosis. PLoS One 8: e65158, 2013.

33. Matsika A, Srinivasan B, Day C, Mader SA, Kiernan DM, Broomfield A, Fu J, Hooper JD, Kench JG and Samaratunga H: Cancer stem cell markers in prostate cancer: An immunohistochemical study of ALDH1, SOX2 and EZH2. Pathology 47: 622-628, 2015.

34. Nishida S, Hirohashi Y, Torigoe T, Inoue R, Kitamura H, Tanaka T, Takahashi A, Asanuma H, Masumori N, Tsukamoto T, et al: Prostate cancer stem-like cells/cancer-initiating cells have an autocrine system of hepatocyte growth factor. Cancer Sci 104: 431-436, 2013.

35. Ieni A and Tuccari G: Comments on the 'Prognostic impact and clinicopathological correlation of CD133 and ALDH1 expression in invasive breast cancer'. J Breast Cancer 19: 96-98, 2016.

36. Vassilopoulos A, Chisholm C, Lahusen T, Zheng H and Deng CX: A critical role of CD29 and CD49f in mediating metastasis for cancer-initiating cells isolated from a Brcal-associated mouse model of breast cancer. Oncogene 33: 5477-5482, 2014.

37. Naka N, Takenaka S, Araki N, Miwa T, Hashimoto N, Yoshioka K, Joyama S, Hamada K, Tsukamoto Y, Tomita Y, et al: Synovial sarcoma is a stem cell malignancy. Stem Cells 28: 1119-1131, 2010.

38. Brett D, Whitehouse S, Antonson P, Shipley J, Cooper C and Goodwin G: The SYT protein involved in the $t(X ; 18)$ synovial sarcoma translocation is a transcriptional activator localised in nuclear bodies. Hum Mol Genet 6: 1559-1564, 1997.

39. Hayakawa K, Ikeya M, Fukuta M, Woltjen K, Tamaki S, Takahara N, Kato T Jr, Sato S, Otsuka T and Toguchida J: Identification of target genes of synovial sarcoma-associated fusion oncoprotein using human pluripotent stem cells. Biochem Biophys Res Commun 432: 713-719, 2013.

40. Cironi L, Provero P, Riggi N, Janiszewska M, Suva D, Suva ML, Kindler V and Stamenkovic I: Epigenetic features of human mesenchymal stem cells determine their permissiveness for induction of relevant transcriptional changes by SYT-SSX1. PLoS One 4: e7904, 2009.

41. Garcia CB, Shaffer CM, Alfaro MP, Smith AL, Sun J, Zhao Z, Young PP, VanSaun MN and Eid JE: Reprogramming of mesenchymal stem cells by the synovial sarcoma-associated oncogene SYT-SSX2. Oncogene 31: 2323-2334, 2012.

42. Saito T: The SYT-SSX fusion protein and histological epithelial differentiation in synovial sarcoma: Relationship with extracellular matrix remodeling. Int J Clin Exp Pathol 6: 2272-2279, 2013. 